\title{
CHEMICALLY MODIFIED PHOTOSYNTHETIC BACTERIAL REACTION CENTERS: CIRCULAR DICHROISM, RAMAN RESONANCE, LOW TEMPERATURE ABSORPTION, FLUORESCENCE AND ODMR SPECTRA AND POLYPEPTIDE COMPOSITION OF BOROHYDRIDE TREATED REACTION CENTERS FROM Rhodobacter sphaeroides R26
}

\author{
D. Beese ${ }^{1 *}$, R. Steiner ${ }^{1}$, H. Scheer ${ }^{1}$, A. Angerhofer ${ }^{2}$, B. Robert ${ }^{3}$ and M. Lutz ${ }^{3}$ \\ 'Botanisches Institut der Universität, Menzinger, Str. 67, D-8000 München 19, W. Germany, \\ 2Physikalisches Institut der Universität, Pfaffenwaldring 57, D-7000 Stuttgart 80, W. Germany, and \\ ${ }^{3}$ Biophysics Department, CENS, Gif-sur-Yvette, France
}

(Received 7 January 1987; accepted 18 August 1987)

\begin{abstract}
Reaction centers from Rhodobacter sphaeroides have been modified by treatment with sodium borohydride similar to the original procedure [Ditson et al., Biochim. Biophys. Acta 766, 623 (1984)], and investigated spectroscopically and by gel electrophoresis.

(1) Low temperature $(1.2 \mathrm{~K})$ absorption, fluorescence, absorption- and fluorescence-detected ODMR, and microwave-induced singlet-triplet absorption difference spectra (MIA) suggest that the treatment produces a spectroscopically homogeneous preparation with one of the 'additional' bacteriochlorophylls being removed. The modification does not alter the zero field splitting parameters of the primary donor triplet ( ${ }^{\mathrm{T} P 870)}$.

(2) From the circular dichroism and Raman resonance spectra in the $1500-1800 \mathrm{~cm}^{-1}$ region, the removed pigment is assigned to $\mathrm{Bchl}_{\mathrm{M}}$, e.g. the "extra" Bchl on the "inactive" $\mathrm{M}$-branch.

(3) A strong coupling among all pigment molecules is deduced from the circular dichroism spectra, because pronounced band-shifts and/or intensity changes occur in the spectral components assigned to all pigments. This is supported by distinct differences among the MIA spectra of untreated and modified reaction centers, as well as by Raman resonance.

(4) The modification is accompanied by partial proteolytic cleavage of the M-subunit. The preparation is thus spectroscopically homogeneous, but biochemically heterogenous.
\end{abstract}

\section{INTRODUCTION}

The reaction center $(\mathrm{RC}) \dagger$ of bacteriochlorophyll $a$ (Bchl a) containing photosynthetic purple bacteria consists of three polypeptides, designated subunits $H, M$ and $L$ according to their electrophoretic mobilities. It contains six chromophores, i.e. 4 molecules Bchl $a$ and 2 molecules bacteriopheophytin $a$ (Bphe $a$ ), two quinones and one iron (Feher and Okamura, 1978; Parson, 1982). Two of the Bchl $a$ molecules (Norris et al., 1975) form the special pair serving as the primary electron donor designated P870 according to its long wavelength absorption around $870 \mathrm{~nm}$. For one of the two Bphe $a-$ molecules absorbing at $760 \mathrm{~nm}$ in the near infrared region, an intermediate acceptor function for the

\footnotetext{
*To whom correspondence should be addressed.
}

$\uparrow$ Abbreviations: Bchl, bacteriochlorophyll; Bphe, bacteriopheophytin; the location on the $L-$ or $M$ subunit of the $\mathrm{RC}$, is indicated by the suffix $\mathrm{L}$ and $\mathrm{M}$, respectively; $C_{\text {., }}$ Chloroflexus; CD, circular dichroism; LDAO, dodecyl dimethylaminoxide; $R b$., Rhodobacter; $\mathrm{RC}$, reaction center; $R p$., Rhodopseudomonas; RR, Raman resonance spectroscopy; SDS-PAGE, sodium dodecyl sulfate polyacrylamide gel electrophoresis; TX-100, Triton X-100. electron during the charge separation has been established (see Parson, 1982 for leading references).

Crystallographic data from the RC of a Bchl $b$ containing purple photosynthetic bacterium, $R p$. viridis (Michel, 1982; Deisenhofer et al., 1984) and from $R b$. sphaeroides (Chang et al., 1986) show a $\mathrm{C} 2$ - symmetry axis which divides the reaction center into two sets of pigments situated mainly on the $\mathrm{L}$ and M-subunit, respectively. The primary charge separation takes place most probably from the special pair situated on the symmetry axis, via $B_{p h e_{L}}$ to $\mathrm{Q}_{\mathrm{L}}$ (formerly $\mathrm{Q}_{\mathrm{A}}$ ) situated on the $\mathrm{L}$ - (or 'active') branch of the complex (Deisenhofer et al., 1984; Vermeglio and Paillotin, 1982; Zinth et al., 1985).

Much less is known on the function of the remaining two monomeric Bchl a molecules absorbing around $800 \mathrm{~nm}\left(\mathrm{Bchl}_{\mathrm{L}}, \mathrm{Bchl}_{\mathrm{M}}\right)$, and of the second pheophytin, Bphe $\mathrm{M}_{\mathrm{M}}$. If judged from its location between the primary donor and $\mathrm{Bphe}_{\mathrm{L}}$ (Deisenhofer et al., 1985; Chang et al., 1986), Bchl should be functional in electron transport between the two. It is still unclear, however, if it acts as the very first acceptor in this process (Shuvalov and Duysens, 1986), or if some other mechanism like super- 
exchange, rapid hopping between a close and a distant site or yet another process is operative (Kirmaier et al., 1985; Ogrodnik et al., 1982; Breton, 1986; Zinth et al., 1985; Knapp et al., 1985; Wasielewski, 1986; Parson, 1982; Michel-Beyerle et al., 1987; Fischer and Scherer, 1987). The participation of the second Bch! $\left(\mathrm{Bchl}_{\mathrm{M}}\right)$ and $\mathrm{Bphe}_{\mathrm{M}}$ situated on the M-branch is unclear. The latter can also accept an electron (Robert et al., 1985; Michel-Beyerle et al., 1987), but it is questionable if this also takes place under physiological conditions.

In view of the tight packaging of the pigments and the highly optimized charge separation, modified $\mathrm{RC}$ are of considerable interest both for the experimentalist and theoretician. The possibility to remove one of the six tetrapyrrolic pigments in bacterial reaction centers (Ditson et al., 1984) provided for the first time an experimental tool to modify the tetrapyrroles in this complex. By treatment with sodium borohydride, about $50 \%$ of the bacteriochlorophyll (Bchl) absorbing at $800 \mathrm{~nm}$ can be removed. From kinetic (Maroti et al., 1985; Holten, 1986; Shuvalov and Duysens, 1986; Breton 1986) and spectroscopic evidence (Robert et al., 1986) it has been suggested that the 'inactive' $\mathrm{Bchl}_{\mathrm{M}}$ on the M-branch (Deisenhofer et al., 1984; Chang et al., 1986), is reduced at the 3-acetyl group and can then be dissociated from the remaining complex (Maroti et al., 1985).

Selective modifications of this type are expected to be very useful in order to better understand the involvement of the different pigments in electron transfer. A basic requirement for evaluating the results is a thorough characterization of the modified preparations with respect to chemical composition, homogeneity, spectroscopy and kinetics. This is of particular importance because the homogeneity of the sample has been questioned more recently by Shuvalov et al. (1986), who discuss a product mixture in which the $\mathrm{Bphe}_{\mathrm{M}}$ is partly reduced. Here we want to present further data characterizing the "missing" Bchl $a$ in $\mathrm{NaBH}_{4}$ treated RC's, as Bchl $\mathrm{M}_{\mathrm{M}}$, which is strongly coupled to the other pigments, together with spectroscopic data supporting the homogeneity of the sample, but also results showing the treatment is prone to produce changes in the polypeptide(s) in addition to the pigment removal.

\section{MATERIALS AND METHODS}

Preparations. Rb. sphaeroides R26 (DSM) was grown in 3001 batch culture at the Gesellschaft für Biotechnologie. (D-3301 Stöckheim). RC's were prepared as described earlier (Feher and Okamura, 1978). Bchl removal was performed according to the original method of Ditson et al. (1985) in the presence of LDAO as detergent. Solid sodium borohydride $(5 \mathrm{mg}=0.13 \mathrm{mmol}$, can be replaced by the potassium salt) was added to the RC's ( $3 \mathrm{ml}$ with $\left.A_{x>1,}=0.4 \mathrm{~cm}^{-1} 9.4 \mathrm{nmol}\right)$ in tris buffer $(10 \mathrm{mM}, \mathrm{pH}=8.0)$ containing LDAO $(0.04 \%=1.7 \mu M)$. The reaction was followed spectrophotometrically in the $300-900 \mathrm{~nm}$ range. To stop the reaction in kinetic experiments, aliquots were diluted $1: 1$ with a glucose solution $(0.2 \mathrm{~g} / \mathrm{m} \ell)$ which destroys excess reagent without affecting the RC. For polypeptide analysis, acetone was added alternatively which also precipitated the protein. For the low temperature spectra, the detergent was exchanged against Triton $\mathrm{X}-100(\mathrm{TX}-100)$. RC $(0.1 \mu \mathrm{mol})$ were dialysed extensively against tris buffer $(20 \mathrm{mM}, \mathrm{pH} 8.0)$ containing TX-100 $(0.1 \%)$, loaded on a DEAE cellulose (DE 52, Whatman) column $(2 \times 8 \mathrm{~cm})$ and subsequently washed with 10 column volumes of buffer. They were then eluted with $\mathrm{NaCl}(190 \mathrm{mM})$ in the same buffer. The typical absorption ratio $A_{801} / A_{x 70}$ is 1.3 . Chemical oxidation of reaction centers was done by titration with potassium ferricyanide.

Chemicals. Dodecyl dimethylaminoxide was from Fluka (Buchs), tris- $\mathrm{HCl}$ and $\mathrm{TX}-100$ from Serva (Heidelberg), $\mathrm{NaBH}_{4}$ and other chemicals from Merck (Darmstadt).

Spectra. Absorption spectra were recorded on a DMR 22 (Zeiss, Oberkochen). Absorption-difference spectra were measured with a ZWS II dual wavelength spectrometer in split-beam mode (Sigma, Berlin) equipped with a red-sensitive photomultiplier and home-built computer system. Extinction coefficients were determined with respect to the $870 \mathrm{~nm}$ transition of $\mathrm{RC}\left(\epsilon=1.28 \times 10^{5}\right.$ $\mathrm{cm}^{-2} M^{-1}$, Clayton and Wang, 1971). Since the intensity of this band remained unchanged during treatment with borohydride, the same value was used for modified RC. Circular dichroism spectra were obtained on a dichrograph V (ISA, Unterhaching) equipped with a silex data-handling system (Leanord, Lille) with a modified software. Wavelength calibration was done with the $360 \mathrm{~nm} \mathrm{Hg}$ line in the near UV and with the $806 \mathrm{~nm}$ band of RC's (Reed and $\mathrm{Ke}, 1975)$ in the near infrared. Spectra of the relaxed state (fully reduced P870) were recorded in the presence of sodium ascorbate ( $1 \mathrm{mM})$ to prevent photooxidation by the measuring light. For the determination of molar ellipticities, the reaction was followed in the CD cuvette, and the decrease at the $870 \mathrm{~nm}$ band then used to calibrate all other bands in purified, modified RC.

Low temperature absorption spectra were taken by a homebuild single-beam spectrometer, using a tungsten iodine lamp $(150 \mathrm{~W})$ for excitation, a Jobin-Yvon HRS.I monochromator for dispersion and either a S1- or a S20type photomultiplier for detection. The transmittance of the optical path without sample was divided by the transmittance with the sample and logarithmized by the computer to yield the optical density of the sample.

Fluorescence emission and excitation spectra were recorded with the same apparatus as described by Angerhofer et al. (1986). Fluorescence-ODMR spectra were measured with the ODMR set-up described earlier (Angerhofer et al., 1985). The same microwave set-up in combination with the above described absorption photometer was used to record absorption-ODMR and microwave induced absorbance (MIA) spectra, the theory of which is described by den Blanken and Hoff (1983) and den Blanken (1983). Correction of the microwave induced transmission with the sample transmission was performed by the computer instead of an analog divider as used by den Blanken (1983)

Resonance Raman spectra were obtained with a setup described earlier in detail (Lutz, 1984; Lutz and Robert, 1985). They were obtained at about $30 \mathrm{~K}$, using the 363,8 $\mathrm{nm}$ line of an Argon-ion laser which insures resonance at the top of the Soret bands of the bacteriochlorin pigments.

$S D S-P A G E$ was done after a modified method of Laemmli (1970) using either a 11.5 to $16.5 \%$ acrylamid gradient gel or a constant $11.5 \%$ gel. Coomassie brilliant blue stained gels were scanned in Vitatron model UR400 scanner. The apparent molecular weights were determined with a set of hydrophilic markers. 


\section{RESULTS}

\section{Absorption spectroscopy}

The titration with $\mathrm{NaBH}_{4}$ was followed by absorption (Figs. 1 and 2) and difference spectroscopy (Fig. 3) in a scattering insensitive system. The reaction mixture becomes slightly turbid during the reaction, and the $800 \mathrm{~nm}$ absorption decreases by about $50 \%$ as compared to its starting value (Fig. 1, traces A,B). A new absorption appears instead at $715 \mathrm{~nm}$, whose intensity varies considerably among different experiments (see shoulder of the short-wavelength side of the $760 \mathrm{~nm}$ absorption band, Fig. 1, trace $B$ ). A second pronounced change occurs in the $Q_{X}$ spectral region between 500 and $630 \mathrm{~nm}$. The Bchl $a$ absorption decreases, and both the $\mathrm{Q}_{\mathrm{X}}$-bands from Bchl and Bphe develop well resolved shoulders at their short-wavelength sides. Frequently, there is also a small absorption band around $480 \mathrm{~nm}$ present in the reaction mixture.

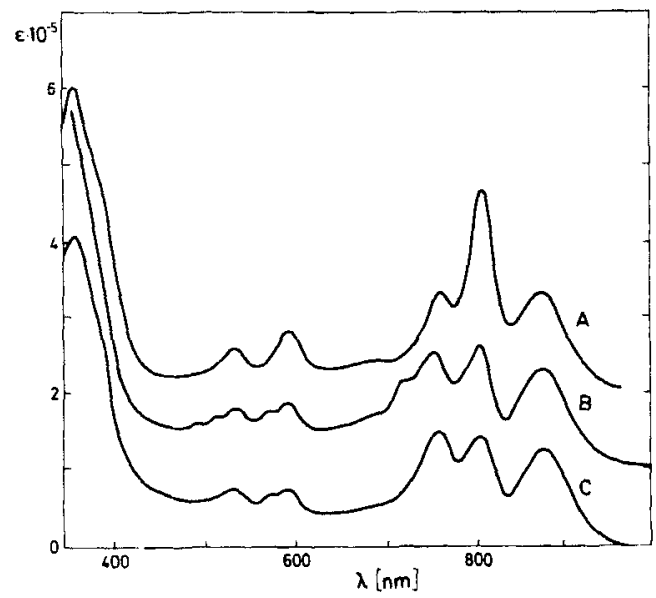

Figure 1. Absorption spectra at $298 \mathrm{~K}$ of reaction centers ( $5 \mu M$ in tris-LDAO buffer) before $(A)$ and $16 \mathrm{~h}$ after (B) the addition of sodium borohydride $(5 \mathrm{mg} / \mathrm{m} /$ solution), and after purification on DEAE cellulose (C). Traces $B$ and $C$ are raised by 1 and $2 \times 10^{5} \mathrm{~cm}^{-2}$, respectively, to avoid extensitive overlap.

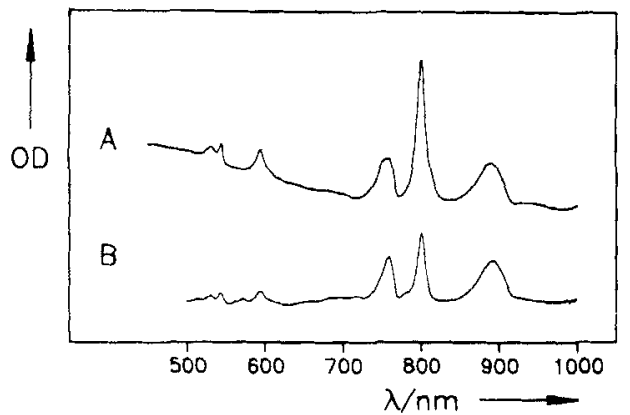

Figure 2. Low temperature absorption spectra $(1.2 \mathrm{~K})$ of modified, purified reaction centers $(B)$ and of the original sample (A).

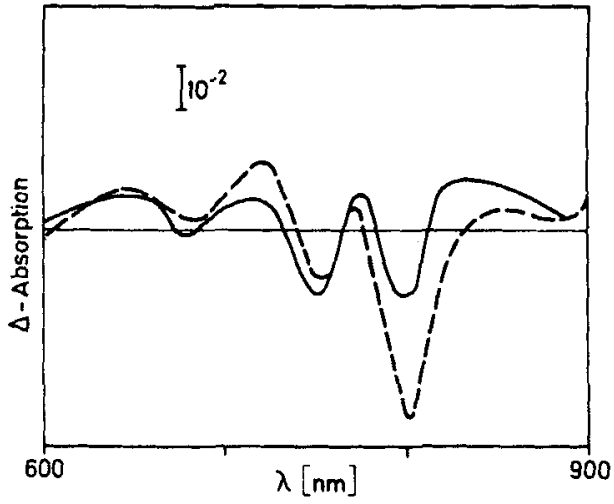

Figure 3. Absorption difference spectra at $298 \mathrm{~K}$ of the reaction of $\mathrm{RCs}$ with sodium borohydride. The spectra were taken $15 \mathrm{~min}(-)$ and $60 \mathrm{~min}(--)$ after addition of reagent, with untreated $\mathrm{RCs}$ as reference. Concentrations as in Fig. 1. Absorption of the original solution was 0.64 at $870 \mathrm{~nm}$.

During purification of the modified RCs on DEAE-cellulose (Maroti et al., 1985), the modified (reduced at $\mathrm{C}-3^{\prime}$ ) pigment(s) are removed as indicated by the disappearance of the respective bands $(715,482$, shoulder $508 \mathrm{~nm})$. At the same time, the previously turbid solutions become clear again, and the ratio $A_{8000} / A_{870}$ is slightly increased. Typical preparations (Fig. 1, trace $\mathrm{C}$ ) have an absorption ratio of 1.3 .

The spectral changes in the tris-LDAO buffer system are principally similar to the ones described by Ditson et al. (1984) in the original procedure. In particular is the decrease of the $800 \mathrm{~nm}$ band more pronounced than in subsequent preparations using a tris/TX-100 buffer system (Maroti et al., 1985; Shuvalov et al., 1986). We found that the decrease of the $800 \mathrm{~nm}$ band is generally faster and more complete in the presence of LDAO. The $800 / 860$ ratio changes from 2.1 to 1.4 within $6 \mathrm{hr}$ and to 1.2 overnight, whereas a value of $1.6-1.8$ was obtained after $24 \mathrm{~h}$ with TX-100.

The most pronounced feature in the low temperature absorption spectra (Fig. 2) is (like in the high temperature spectra) a decrease of the $800 \mathrm{~nm}$ band due to the loss of the $\mathrm{Bchl}_{\mathrm{M}}$ pigment. In addition, there are some differences resolved which were not discernible in the room temperature spectra (Maroti et al., 1985). Two minor bands become apparent at 780 and $572 \mathrm{~nm}$, and the shape of the Bphe band at $757 \mathrm{~nm}$ is different. Instead of consisting of two poorly resolved bands of equal intensity, it now appears to be a main band shifted to longer wavelengths with a short-wavelength shoulder.

The absorption difference spectra taken at later stages of the reaction ( $\geq 60 \mathrm{~min}$ after borohydride addition, Fig. 3) reflect the absorption changes described above, but show as additional features a distinct positive maximum at $717 \mathrm{~nm}$ and a smaller one at $770 \mathrm{~nm}$, together with negative bands at 800 and $750 \mathrm{~nm}$. The $Q_{X}$ region (data not shown) is 
difficult to evaluate quantitatively because of the turbidity. Qualitatively, negative peaks are indicated at 580 and $530 \mathrm{~nm}$ and positive ones at 570 and $525 \mathrm{~nm}$. In samples originally contaminated with a 2-deethyl-2-acetyl-chlorophyll $a$ (Smith and Calvin, 1966), an additional negative peak around $680 \mathrm{~nm}$ appears corresponding to the reduction product(s) of the latter. The broad features in the 620-680 nm region are probably related to the products of this reaction (Steiner $e t$ al., unpublished). Similar features are also seen in the published literature (see e.g. Fig. 2c of Maroti et al., 1985).

The difference spectra at early stages of the reaction with $\mathrm{NaBH}_{4}$ show a somewhat different pattern (Fig. 3). The two negative bands around 800 and $755 \mathrm{~nm}$ are of equal intensity. There is also a broad positive band above $800 \mathrm{~nm}$. Its maximum is at shorter wavelengths than the $\mathrm{P} 870$. minus $\mathrm{P} 870$ difference spectrum (Clayton, 1980), which indicates that it does not arise from some oxidized P870 being present and then becoming reduced at the beginning of the experiment.

Since the reaction is accompanied by an increase of the $\mathrm{pH}$ to $10-10.5$, the effect of high $\mathrm{pH}$ alone was tested in an independent experiment. Up to $\mathrm{pH}$ 10.5 , the spectrum remains unchanged. At $\mathrm{pH} \geq 11$, the absorption around $860 \mathrm{~nm}$ decreases first, accompanied by an increasing absorption at 760 to $770 \mathrm{~nm}$. At even higher $\mathrm{pH}$ values $(\mathrm{pH} 12.0)$ both the 860 and $800 \mathrm{~nm}$ bands diminish completely.

\section{Fluorescence}

The excitation spectra of the P870 fluorescence at low temperatures (Fig. 4) are similar to the absorption spectra. The decrease of the $803 \mathrm{~nm}$ band is rather distinct, and a new band at $574 \mathrm{~nm}$ is clearly resolved. There is also a change in the 870

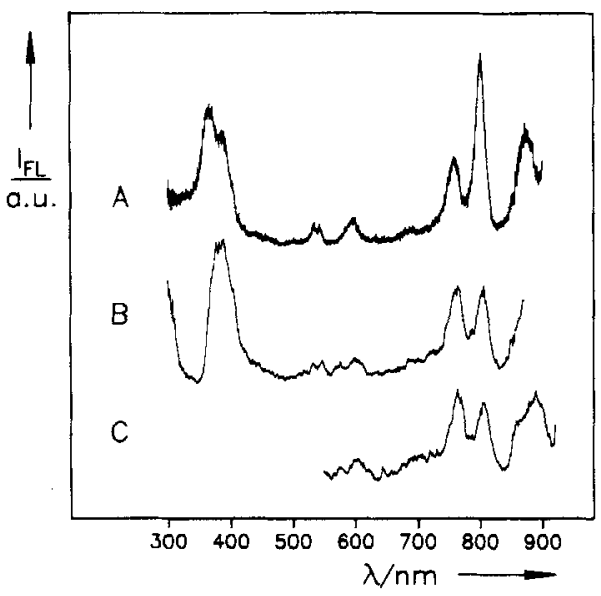

Figure 4. Fluorescence excitation spectra $(1.2 \mathrm{~K})$ of modified reaction centers $(B, C)$ and of the original sample before treatment with sodium borohydride (A). Emission wavelengths $920(\mathrm{~A}, \mathrm{~B})$ and $933 \mathrm{~nm}(\mathrm{C})$. Spectra are not corrected for instrument response. nm band, which becomes structured and broadened in the modified RC.

The emission spectra in the near infrared show two bands (Fig. 5). One at $917 \mathrm{~nm}$ is due to the reaction center, which is only weakly fluorescent. The one around $776 \mathrm{~nm}$ arises from contamination with free (= non-aggregated) pigments, Bchl and Bphe, as evidenced by the excitation spectra (not shown). They are strongly fluorescent and thus picked up with high sensitivity in the RC, which is only weakly fluorescent itself. The only significant change of the sample after modification with sodium borohydride, is an increase of this free pigment emission by approximately $150 \%$. This is still at the lower limit of detection by absorption spectroscopy, and is probably responsible for the increase of absorption at 770 as compared to $870 \mathrm{~nm}$ in the modified sample (Fig. 1).

\section{Optically detected magnetic resonance}

The fluorescence detected ODMR spectra (Fig. 6) support this interpretation. At short detection wavelengths, the spectra are related to a triplet with transitions at $500(+)$ and $903 \mathrm{MHz}(-)$ characteristic of free Bchl (Beck et al., 1983a). In the longwavelength band, the triplet transitions are negative $(474,665 \mathrm{MHz}$ ) below $900 \mathrm{~nm}$ and change sign about $910 \mathrm{~nm}(474,670 \mathrm{MHz})$. These two triplet signals with slightly different zero-field splittings and the sign reversal between 900 and $910 \mathrm{~nm}$ are typical for RC (Beck et al., 1983b; Angerhofer et al., 1984). The spectra of unmodified and modified $\mathrm{RC}$ are identical within the experimental error.

The absorption detected ODMR spectra (not shown) of $R b$. sphaeroides RC show only two lines which are identical over the long wave-length $\left(\lambda_{\max }\right.$ $=870 \mathrm{~nm}$ ) absorption band, and whose intensity follows the profile of this band. The transitions are both positive and have the same zero field splitting parameters as the triplet detected by fluorescence

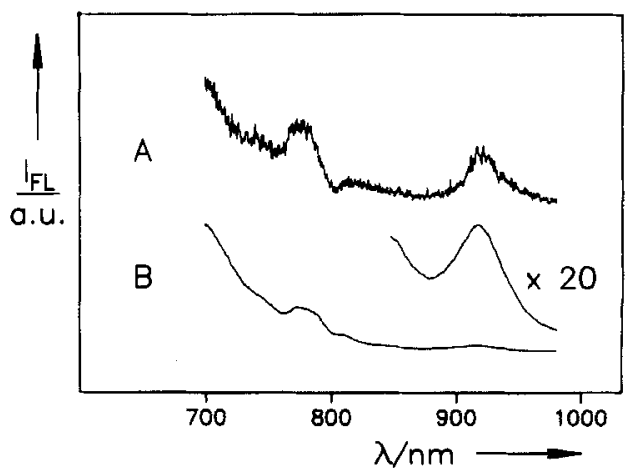

Figure 5. Fluorescence emission spectra $(1.2 \mathrm{~K})$ of modified reaction centers $(B)$ and of the original sample before treatment with sodim borohydride (A). Excitation wavelength $390 \mathrm{~nm}$. The inset is an amplification (20 fold) of trace $(B)$ 

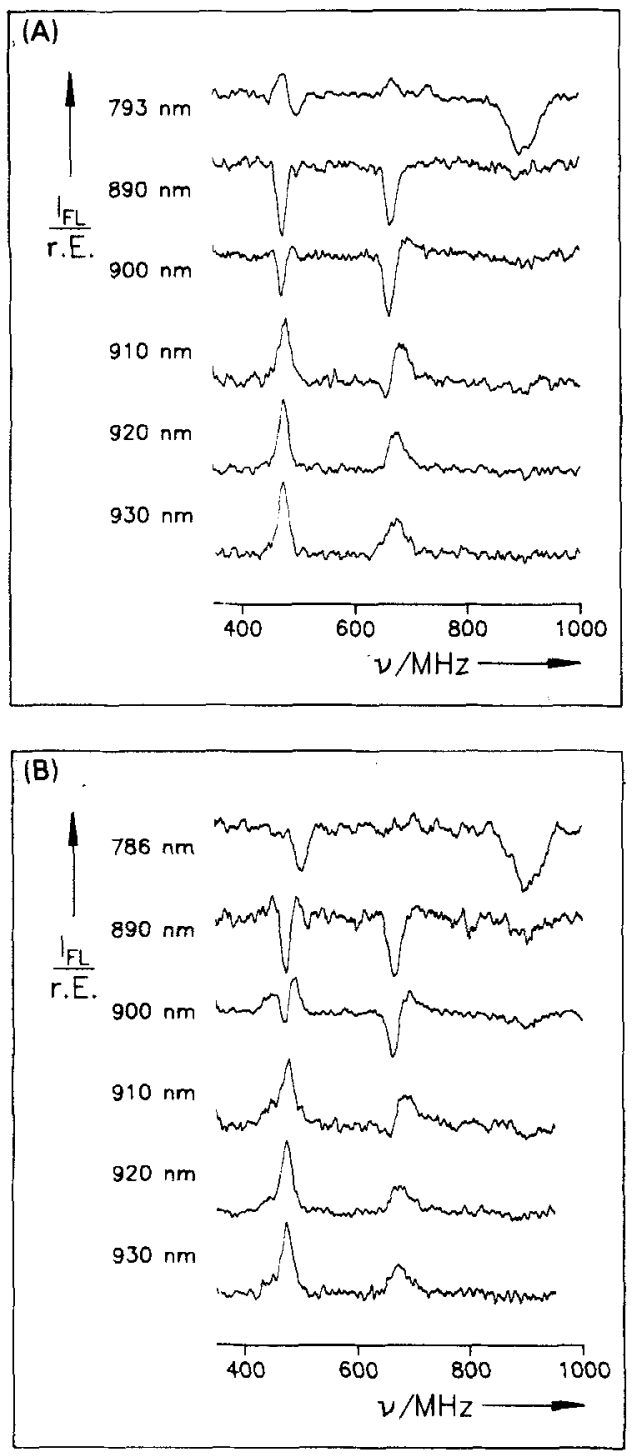

Figure 6. Fluorescence detected magnetic resonance spectra $(1.2 \mathrm{~K})$ at zero field of modified reaction centers $(B)$ and of the sample before treatment with sodium borohy. dride (A). The detection wavelengths for the different traces are given in the insets. See materials and methods for experimental details.

ODMR at detection wavelengths $\leqslant 900 \mathrm{~nm}$. Here again, the spectra of modified and unmodified RC are identical within the experimental error.

\section{Microwave induced absorption difference}

Significant differences between the two species occur in the microwave induced absorption difference spectra (MIA, also referred to as singlet triplet absorption difference by other authors, see e.g. Hoff 1986). Besides the intense band at $890 \mathrm{~nm}$ corresponding to the absorption of the primary donor, it shows a series of narrow bands in the 800 $\mathrm{nm}$ region. The absorption changes are identical for the $|\mathrm{D}+\mathrm{E}|$ and the $|\mathrm{D}-\mathrm{E}|$ transitions, although the signal-to-noise ratio is better in the latter shown in Fig. 7 , trace $\mathrm{C}$. In modified $\mathrm{RC}$, this region shows distinct changes. There is in particular a new positive band at $805 \mathrm{~nm}$ and a decrease around $795 \mathrm{~nm}$. These changes become more clearly discernible in the difference spectrum (Fig. 7c). In addition to a dispersive signal at 797 and $802 \mathrm{~nm}$ there is a small positive signal at 763 and a negative signal (corresponding to an increase in singlet absorption in the modified RC) at $815 \mathrm{~nm}$.

\section{Circular dichroism}

The untreated sample (Fig. 8) shows the wellknown dichroitic absorption maxima at $860(+), 811$ $(-)$ and $795(+)$ and a structured negative signal at $748 \mathrm{~nm}$ [Philipson and Sauer, 1973; Reed and Ke, 1973. In the modified RC the S-shaped signal is shifted to shorter wavelengths $809(-)$ and $779 \mathrm{~nm}$ $(+)]$. A distinct shoulder $(-)$ becomes visible at 830 $\mathrm{nm}$, and a new positive band appears at a position where the original sample had only a negative shoulder $(762 \mathrm{~nm})$. Less pronounced differences between treated and untreated RCs were found in the $\mathrm{Q}_{\mathrm{X}}$-region. Here the untreated sample shows extrema at $601(+)$ and $631 \mathrm{~nm}(-)$. They are slightly blue shifted in the modified sample, and the minor one at $574 \mathrm{~nm}(-)$ is increased in intensity (Fig. 8). The minor positive band in the Bphe $\mathrm{Q}_{\mathrm{X}^{-}}$ region of untreated RC's has disappeared in the treated ones. The changes in the Soret region are even less pronounced. A minor shift becomes apparent only in the difference spectrum (not shown).

Quantitatively, the intensity of most bands is diminished. In the near infrared region, the positive peak at $860 \mathrm{~nm}$ commonly assigned to the special pair is decreased to $42 \%$ in treated RCs as compared to untreated RCs, the intensity of the S-shaped

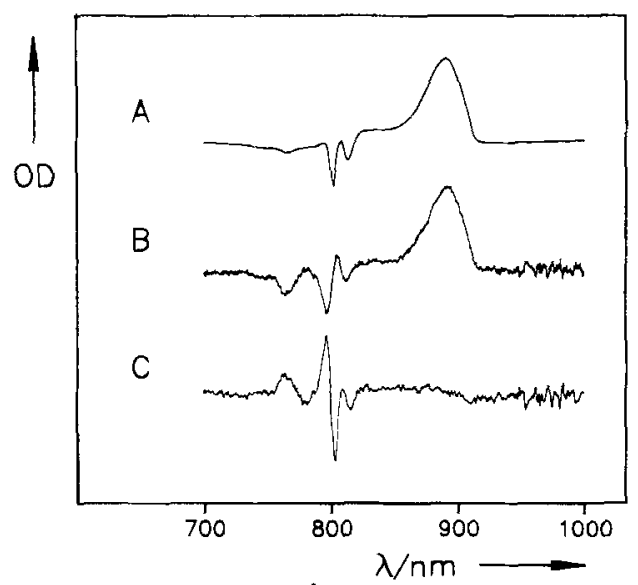

Figure 7. Microwave induced singlet triplet absorption difference spectra (MIA), at $1.2 \mathrm{~K}$ of modified RC (B) and of the original sample before treatment with sodium borohydride (A). Difference of the two spectra (C). All spectra were detected at the $|D-E|$ transition. 


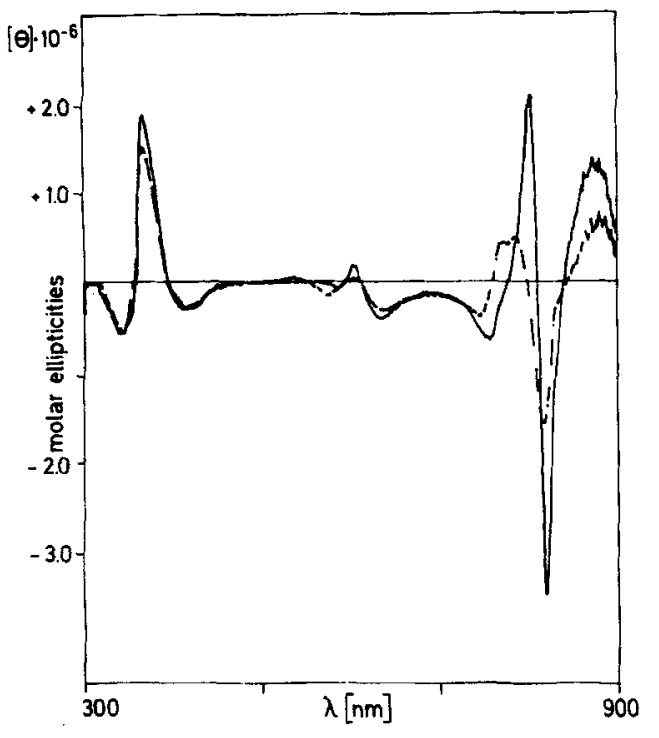

Figure 8. Circular dichroism at $298 \mathrm{~K}$ of $\mathrm{RC}$ in the relaxed state in the presence of sodium ascorbate $(\operatorname{lm} M)$. Before treatment with sodium borohydride (-), and after treatment and purification on DEAE cellulose (-.-).

See Table 1 for wavelengths and molar ellipticities.

signal is even decreased to $37 \%$. This reduced intensity of the strongest bands may be a major reason for the more structured CD spectra. Two bands in the $O_{X}$ region are decreased in intensity as well. The most significant change in this region is an increase of the negative extremum at $574 \mathrm{~nm}$.

The CD spectra of chemically oxidized RC show the most pronounced changes in the $800 \mathrm{~nm}$ region (Fig. 9). The positive band at $799 \mathrm{~nm}$ which dominates the spectrum of the untreated $\mathrm{RC}$, is decreased to $27 \%$, and blue-shifted. Smaller changes include the shift of the negative band

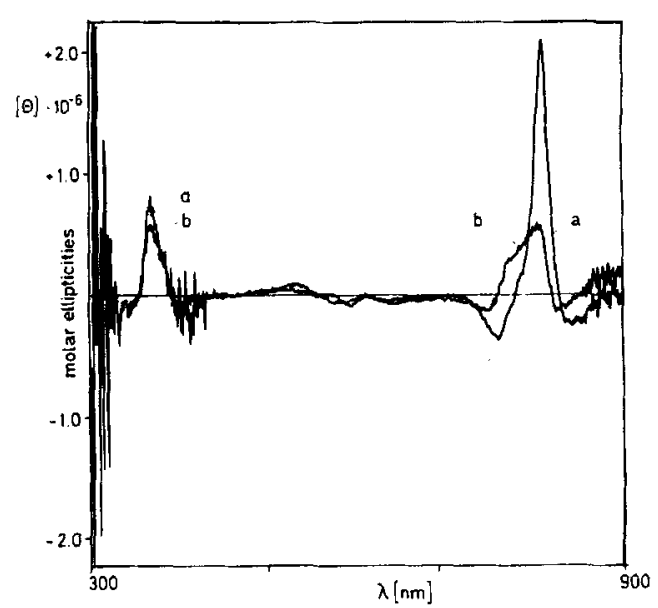

Figure 9. Circular dichroism at $298 \mathrm{~K}$ of $\mathrm{RC}$ in their oxidized sate ( $\mathrm{P} 870^{\circ}$ before (a) and after (b) treatment with sodium borohydride and purification on DEAE cellulose. See Table 1 for wavelengths and molar ellipticities.

around 762 to $738 \mathrm{~nm}$, and the appearance of a short wave-length shoulder of the $800 \mathrm{~nm}$ band. Again, the changes in the other spectral regions are much less pronounced.

\section{Raman-resonance spectroscopy}

The Raman resonance (RR) spectra in the $1550-1750 \mathrm{~cm}^{-1}$ spectral range of both untreated and borohydride treated RC are shown in Fig. 10 . Treatment of the RC with borohydride results in a distinctive enhancement of the $1590 \mathrm{~cm}^{-1}$ band relative to the $1615 \mathrm{~cm}^{-1}$ one, indicating a decrease in Bchl concentration relatively to Bphe concentration. Similar quantitative changes are also observed in other regions of the RR spectra (not shown). The changes are more clearly seen in the

Table 1. Circular dichroism spectra [wavelength in $\mathrm{nm}$ (molar ellipticities $\times 10^{-0}$ in deg. $\left.\left.\mathrm{cm}^{-2} \cdot \mathrm{mol}^{-1}\right)\right]$ of unmodified and modified reaction centers

\begin{tabular}{llll}
\hline & \multicolumn{2}{c}{ Relaxed state } & \multicolumn{2}{c}{ Oxidized state } \\
\cline { 2 - 2 } & Modified & Unmodified & Modified \\
\hline $340(-0.57)$ & $342(-0.56)$ & $369(+0.79)$ & $341(-0.13)$ \\
$369(+1.88)$ & $368(+1.52)$ & $334(-0.43)$ & $369(+5.65)$ \\
$420(-0.29)$ & $420(-0.26)$ & $399(-0.21)$ & $405(-0.15)$ \\
& & & $398(-7.52)$ \\
$601(0.17)$ & $574(-0.15)$ & $591(-0.11)$ & $574(-0.09)$ \\
$631(-0.41)$ & $631(-0.32)$ & & $586(-0.09)$ \\
$748(-0.67)$ & $737(-0.40)$ & $751(-0.40)$ & $738(-0.034)$ \\
$795(+2.07)$ & $762(+0.41)$ & $799(+2.09)$ & $792(+0.56)$ \\
$811(-3.52)$ & $779(+0.48)$ & $829(-0.28)$ & $812(-0.17)$ \\
$860(+1.34)$ & $809(-1.60)$ & & $857(+0.20)$ \\
& $860(+0.56)$ & & \\
\hline
\end{tabular}

Relaxed state in the presence of sodium ascorbate $(1 \mathrm{~m} M)$, oxidized state in the presence of potassium ferricyanide $(50 \mathrm{mM})$. Concentrations determined from A870 with molar absorptivity $=1.28 \times 10^{5} \mathrm{~cm}^{-1} M^{-1}$ (Clayton and Wang, 1971). 


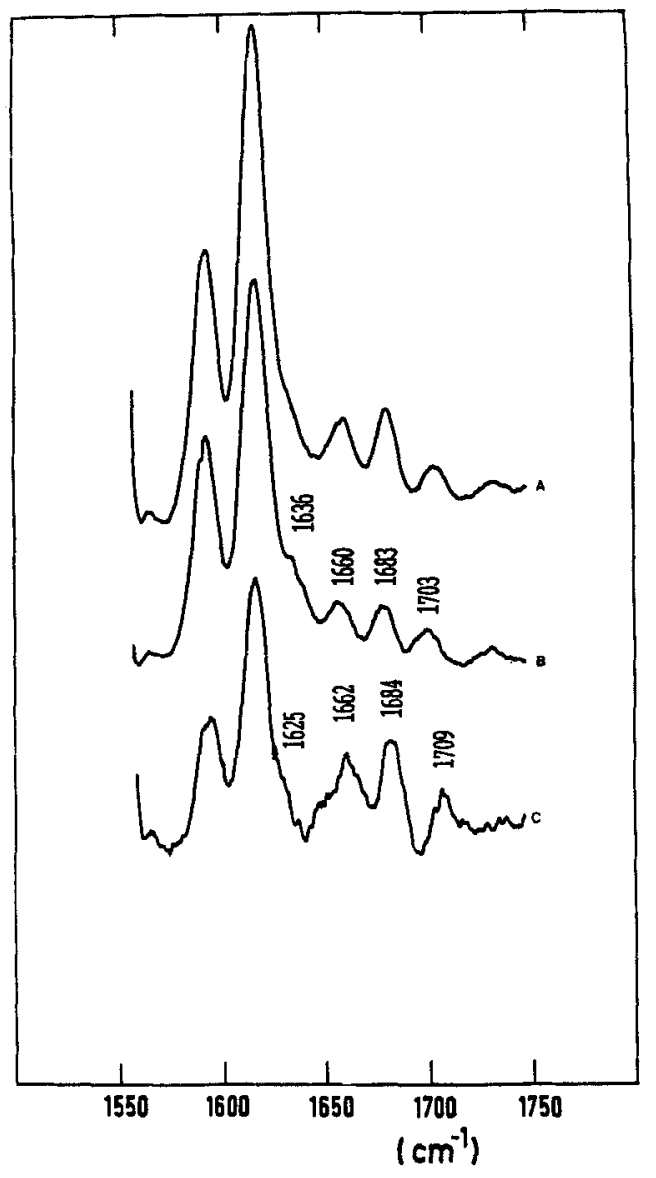

Figure 10. Raman resonance spectra of RCs before (a) and after treatment with sodium borohydride and purification on DEAE cellulose (b). Difference (a minus b) of the two spectra (c).

difference spectrum between untreated and borohydride treated RC (Fig. 10c). For this computation spectra have been properly weighted, by taking into account that the $1700 \mathrm{~cm}^{-1}$ band arises purely from the $535 \mathrm{~nm}$ absorbing Bphe (Lutz and Robert, 1985). This difference spectrum displays two bands at 1663 and $1680 \mathrm{~cm}^{-1}$ and two small S-shaped signals corresponding to shifts of bands occurring in untreated $\mathrm{RC}$ at 1700 and $1625 \mathrm{~cm}^{-1}$.

\section{SDS-polyacrylamide gel electrophoresis}

The studies pertaining to a change in the protein moiety were initiated by a chance observation. During routine tests for the polypeptide composition of $\mathrm{RC}$ after the borohydride treatment, we noticed an unusual band in SDS-polyacrylamide electrophoresis. The untreated samples show three peptides $(\mathrm{H}, \mathrm{M}$ and $\mathrm{L}$ with apparent $\mathrm{MW} 28,24$ and $21 \mathrm{kDa}$, respectively), whereas in the treated ones an additional peptide fragment appears with an apparant $\mathrm{MW}$ of about $15.0 \mathrm{kDa}$ (Fig. 11). At the same time, the intensity of the $\mathrm{M}$ band diminished, which suggest the latter as the origin of the new peptide with an apparent $\mathrm{MW}$ of $15 \mathrm{kDa}$. In view of the high $\mathrm{pH}(10-10.5)$ attained during the reaction with $\mathrm{NaBH}_{4}$, control samples were subjected to $\mathrm{pH} 11$ without addition of the reagent. Under these conditions, the additional polypeptide did not appear (Fig. 11). This indicates that only the $\mathrm{NaBH}_{4}$-reduction but not the accompanying $\mathrm{pH}$ change leads to the cleavage of the peptide.

\section{DISCUSSION}

\section{Homogeneity of the preparation}

It had originally been proposed that the modification with sodium borohydride produces a species which lacks one of the Bchl pigments (Ditson et al., 1984). There are, however, some questions about this straightforward interpretation. One is, that a modified pheophytin rather than the respective chlorophyll has been extracted from the reaction

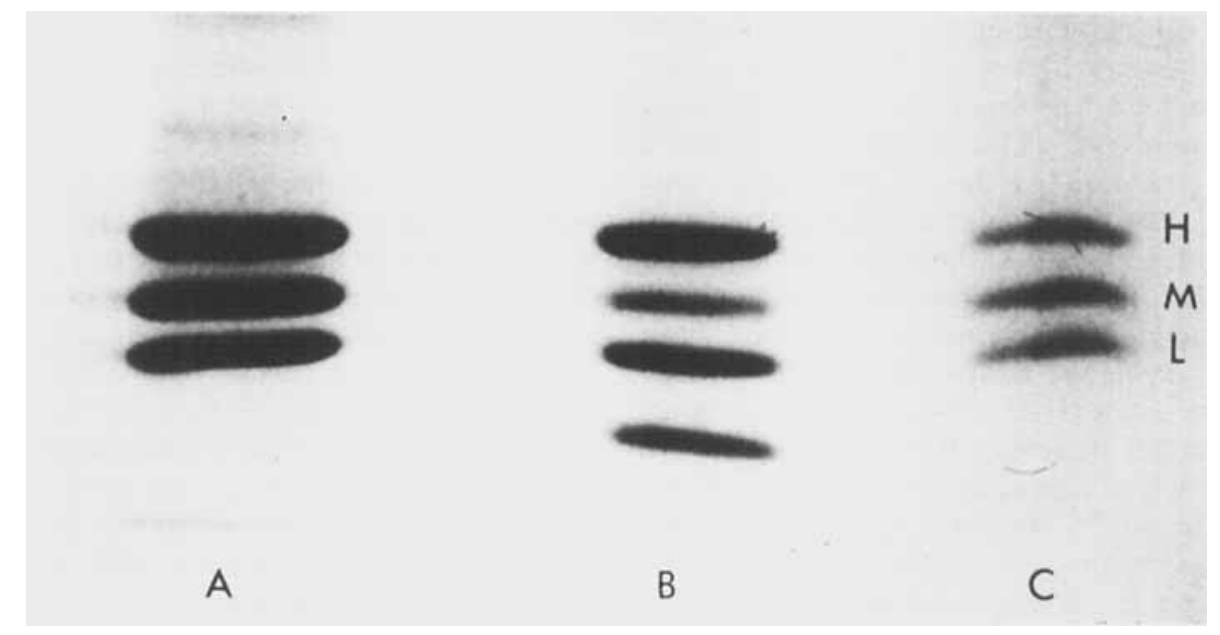

Figure 11. SDS polyacrylamide gel electrophoresis of RCs before (trace A) and after treatment with sodium borohydride for $16 \mathrm{~h}$ (trace $\mathrm{B}$ ), and after incubation at $\mathrm{pH} 1 \mathrm{l}$ for the same time (trace $\mathrm{C}$ ). Gels stained with Coomassie brilliant blue. 
mixture (Maroti et al., 1985), although pheophytinization is unlikely at the high $\mathrm{pH}$ of the reaction. Shuvalov et al. (1986) have subsequently presented rather different conclusions on the identity of the preparation. Based on a comparison with $\mathrm{RC}$ from Chloroflexus (C.) aurantiacus, they suggested the presence of three species in the preparations: One (comprising about $40 \%$ of the mixture) containing a bacteriopheophytin of unspecified structure at the site of $\mathrm{Bchl}_{\mathrm{M}}$, a second one (also about $40 \%$ ) containing neither $B \mathrm{Bchl}_{M}$ nor $B$ phe $\mathrm{M}_{\mathrm{M}}$, and finally unmodified $\mathrm{RC}(20 \%)$. According to their argument, none of the species present would be the one lacking only $\mathrm{Bchl}_{\mathrm{M}}$. The samples of these authors have been prepared in the same buffer system (LDAO as detergent) as used originally by Ditson et al. (1984), but the reaction has been stopped at an earlier stage, and the relative absorptions of the near infrared bands are different from ours. The situation is further complicated by our finding that the pigment modification is accompanied by a protein modification, more specifically by an apparent cleavage of a portion of the $\mathrm{M}$-subunit (vide infra).

In view of the potential importance of the modified RC, it is then crucial to establish their homogeneity both in biochemical and in spectroscopic terms. Since $\mathrm{Bchl}_{\mathrm{M}}$ is apart less than $5 \mathrm{~A}$ from the special pair, e.g. P870, it is expected that any change in its structure or its removal should lead to changes in the spectroscopic properties. We have therefore concentrated in the current work on methods which are sensitive to the state of $\mathbf{P 8 7 0}$ and to the homogeneity of the sample.

The most obvious contamination are free tetrapyrroles still adsorbed to the RC. If judged from the fluorescence emission in the near infrared, the same residual pigments, e.g. "free" Bchl and Bphe, are present both in modified and unmodified RC, although their amount is increased by a factor of 2.5 in the modified ones. In view of the high sensitivity of fluorescence spectroscopy for free pigments, we consider this impurity insignificant, however. By the same argument, fluorescence is then unsuited to detect any small contaminations having as low fluorescence yields as the intact complex. However, a mixture like the one discussed by Shuvalov et al. (1986) containing roughly equal amounts of three different species, should be visible if these species differ in their fluorescence spectra.

Magneto-optical double resonance methods have been used among the most sensitive tools to study the primary donor (Hoff, 1986). It has been shown by fluorescence detected ODMR, that there are (besides any free pigments) generally at least two triplets detected at long wavelengths in $R C$ of two different photosynthetic bacteria, e.g. $R b$. sphaeroides (Beck et al., 1993b; den Blanken, 1983; den Blanken and Hoff, 1983) and Rp. viridis (Angerhofer et al., 1984). The origin of these two slightly different signals with different signs is still under discussion, but at least one of them visible also by absorption detection, is due to the triplet of the primary donors, P870 and P960, respectively. The modified sample shows identical fluorescence detected spectra with untreated RC. There is in particular no additional signal above $800 \mathrm{~nm}$ detection wavelength, and at shorter wavelengths there is only the signal which is typical for free pigments. In absorption mode, too, the modified sample is identical to the original one. If there were any mixture of different species present, the zero field splitting parameters and population-depopulation kinetics of their primary donors would then have to be very similar to each other. One of the species suggested by Shuvalov et al. (1986) has a pigment composition similar to $\mathrm{RC}$ from $C$. aurantiacus, whose zero-field splitting (zfs) values differ from those of $R b$. sphaeroides. This species also shows a rather different MIA-spectrum (den Blanken $e t$ al., 1983). Between 750 and $850 \mathrm{~nm}$ it shows a single strong absorption at $807 \mathrm{~nm}$, a rather broad band around $770 \mathrm{~nm}$ with less intensity and additionally small bleaching at about $818 \mathrm{~nm}$. From these characteristic features which were not reproduced in the modified RC from $R h$. sphaeroides, it can be excluded that $40 \%$ of the RC-preparation have a structure similar to the ones of $C$. aurantiacus.

The finding of a protein modification in addition to the removal of one pigment molecule, makes the situation more complex again. Presently, we interpret this as a selective cleavage of one of the three $\mathrm{RC}$ subunits, e.g. $\mathrm{M}$, since the $15 \mathrm{kDa}$ band decreases the expense of the M-band. The possibility of proteolytic side reactions with sodium borohydride is documented (see e.g. Crestfield et al., 1962). It should be noted, however, that the MW of hydrophobic polypeptides as estimated by SDS-PAGE is prone to considerable error (see e.g. the membrane polypeptides of photosynthetic bacterial membranes; Theiler et al., 1984). Other modifications than cleavage can therefore presently not be excluded rigorously. Whatever the cause of the reaction, it is a result of the borohydride treatment rather than of the increasing $\mathrm{pH}$ that accompanies the reaction. Treatment of $\mathrm{RC}$ at high $\mathrm{pH}$ does not alter the polypeptide pattern even if the reaction center is already denatured $(\mathrm{pH}>11)$. In view of the importance of the $\mathrm{NaBH}_{4}$ reaction, the identity of the new polypeptide is currently explored.

In principle two different mechanisms could then be operative during reaction with borohydride. One is that all spectroscopic changes are essentially due to the removal of the pigment, and the spectroscopic changes induced by the protein modification are negligible. The other one is just the opposite. The protein modification induces such pronounced changes in the arrangement or environment of the remaining pigments, that these dominate the spectroscopy. The extreme of the second mechanism would not be unlikely in view of the tight packing 
of the pigments in RC. Since the decrease of the intensity of $\mathrm{M}$, and the concomitant increase of the $15 \mathrm{kDa}$ band, amount to less than $40 \%$ at the end of the reaction, the final preparation should then be a mixture of two spectrally different products. This possibility is disfavored, however, by the spectroscopic results discussed above, which gave no indications of such a mixture being present. This leaves the first proposal, e.g. that spectroscopic changes induced by proteolysis (?) are insignificant at least as far as the methods applied are concerned. This result would be in line with earlier studies on Bchl proteins including RC from several bacteria, which showed remarkably little effects of proteolysis on their spectra and function (Wiemken and Bachofen, 1984; Steiner et al., 1986).

\section{Assignment of the pigment removed}

The changes in the high (Fig. 1) and low temperature absorption spectra (Fig. 2) upon treatment with borohydride seem to be very simple (see below, however): there is a decrease of the $800 \mathrm{~nm} \mathrm{Q}_{\mathrm{y}}$ absorption band by approx. $40 \%$ and a decrease and split of the $\mathrm{Q}_{\mathrm{X}}$ band around $580 \mathrm{~nm}$. In untreated $\mathrm{RC}$, the $800 \mathrm{~nm}$ band arises mainly from the two extra Bchl molecules, but other pigments, in particular P870, contribute to it. A decrease of this band by $40 \%$, as well as the decrease of the $Q_{X}$ band would then be compatible with the removal of one of the two Bchl.

An assignment of the pigment removed to $\mathrm{Bchl}_{\mathrm{M}}$, can be made from several lines of arguments. The first is based on the CD spectra, which show much more pronounced changes than the absorption spectra (Figs. 8 and 9). Essentially all bands in the near infrared region are effected by the treatment, and the decrease in signal intensity is considerably more than expected for removal of a single, isolated pigment. Shuvalov et al. (1986) recently presented similar spectra of $\mathrm{NaBH}_{4}$ treated RC. There are, however, distinct quantitative differences, the most significant one being that these authors found the intensity of the $870 \mathrm{~nm}$ band unchanged. This may reflect the different preparations. Since the relative band intensities in both preparations are rather similar, it is more likely, however, that the spectra of Shuvalov et al. are normalized to equal intensities of the $870 \mathrm{~nm} \mathrm{CD}$ band. In the figure legend, this is only indicated for the low temperature spectra, however. (See note added in proof.)

The two pigments $B c h l_{L}$ and $B c h l_{M}$ are situated between P870, and the Bphe $e_{L}$ and $B p h e_{M}$ molecules, respectively. The most pronounced effects upon removal of one of them are then expected on the immediate neighbors, e.g. $\mathrm{P} 870$ and $\mathrm{Bphe}_{\mathrm{M}}$ or Bphe $_{\mathrm{L}}$, respectively. The decrease of the $870 \mathrm{~nm}$ band then reflects the former interactions. The changes in the Bphe spectral region can be used to locate the removed pigment on the $\mathrm{M}$-branch. The
$\mathrm{CD}$ spectrum of untreated $\mathrm{RC}$ show two poorly resolved negative bands in this region, which are present both in the reduced (P870) and the oxidized (P870 ) complex. The major one is located at 757 $\mathrm{nm}$ and blue-shifted in the treated complex. The smaller one at longer wavelengths (shoulder at 773 $\mathrm{nm}$ ) shows an apparent sign inversion, although it may be positive and superimposed on the stronger, negative band in the untreated $R C$. The absorptions of the two Bphe in the $Q_{y}$-region are only poorly separated, with Bphe $_{\mathrm{L}}$ absorbing at $760 \mathrm{~nm}$, and $\mathrm{Bphe}_{\mathrm{M}}$ at somewhat shorter wavelengths. The pronounced blue-shift of the latter would then place the removed Bchl on the M-branch. Unfortunately, the optical activity of the Bphe's is too small in the $Q_{X}$ region to further evaluate this assignment.

The second line of arguments is based on the Raman resonance data. The frequency range presented in the results (Fig. 10) contains bands arising from double bond stretching modes, from which much information can be extracted: A methine bridge stretching mode of the Bchls occurs around $1615 \mathrm{~cm}^{-1}$, the frequency of which has been shown to be sensitive to the number (one or two) of axial ligands on the central $\mathrm{Mg}$ atom (Lutz and Robert, 1985). The stretching modes of the 2-acetyl and 9keto carbonyls conjugated to the bacteriochlorin $\pi$ systems also occurs in this range $\left(1620-1720 \mathrm{~cm}^{-1}\right)$. These groups are present both in Bchl and Bphe and have been shown to play a key role in the intermolecular interactions of these pigments both in vivo and in vitro (Lutz and Robert, 1987). It was shown, that the $1590 \mathrm{~cm}^{-1}$ band arises mainly from Bphe, and the relative intensity ratio between the 1590 and $1615 \mathrm{~cm}^{-1}$ band can yield information about the $\mathrm{Bchl} / \mathrm{Bphe}$ ratio.

The decrease of the $1615 \mathrm{~cm}^{-1}$ band then reflects the removal of the Bchl (B800). This is further corroborated by bands in other spectral regions which are specific for either Bchl or Bphe. The former bands are always weakened relatively to the bands purely arising from Bphe (data not shown). The disappearance of two carbonyl groups in the difference spectrum corresponds to the removal of one and only one pigment in the RCs. Moreover, the possibility to compute this difference spectrum indicates that no important change in the Soret bands happens during this bleaching; otherwise no normalization between the spectra of Fig. 10 resulting in a coherent difference spectrum could have been done.

Based on this bleaching, it is now possible to assign the $\mathrm{CO}$ bands in the removed $\mathrm{Bchl}$ and at the same time infer their bonding states. The accessory Bchl that is removed upon borohydride treatment has one carbonyl band at 1662 , and one at $1684 \mathrm{~cm}^{-1}$. The former one is assigned to the 3acetyl group, because in vitro studies with $\mathrm{Bchl} a$ have shown this group between 1620 and $1660 \mathrm{~cm}^{-1}$, depending on its binding state. Its occurrence at 
$1662 \mathrm{~cm}^{-1}$ then indicates that the 3-acetyl group is free in the Bchl removed. The band at $1684 \mathrm{~cm}^{-1}$ is assigned to the $13^{\mathrm{l}}$-keto group, which is at a frequency indicative of its being engaged in weak (or no) intermolecular interactions.

A more detailed inspection of the difference spectrum makes it clear, that borohydride treatment induces structural changes in the local environments of other pigments in addition to the bleaching of one accesssory $\mathrm{Bchl}$. Indeed, the 1625 and 1700 $\mathrm{cm}^{-1}$ bands, both corresponding to the carbonyl stretching modes of the $535 \mathrm{~nm}$ absorbing Bphe $_{M}$ (Lutz and Robert, 1985) shift by a few $\mathrm{cm}^{-1}$ (less than $2 \mathrm{~cm}^{-1}$ upshift for the $1625 \mathrm{~cm}^{-1}$, and $4 \mathrm{~cm}^{-1}$ downshift for the $1700 \mathrm{~cm}^{-1}$ band). From this fact, it can first be concluded, that the missing Bchl in borohydride treated RCs is most probably the one which is bound to the $\mathrm{M}$ branch, as the signals which appear the most influenced by the treatment are both due to $B$ phe $e_{M}$. The shifts of the $B$ phe related bands are too small to correspond to any qualitative change in the liganding of the carbonyl groups; in particular, the keto group, which is free from bonding in untreated $\mathrm{RC}\left(1708 \mathrm{~cm}^{-1}\right)$ remains free upon borohydride treatment $\left(1703 \mathrm{~cm}^{-1}\right)$. These changes may be induced directly by the removal of the $\mathrm{Bchl}_{\mathrm{M}}$ molecule, and its possible "replacement" by solvent molecules. Alternatively, they may as well be induced indirectly by this removal and result from local rearrangement of the protein around the molecule, involving e.g. displacement of a charged or aromatic residue. Such a rearrangement may be related to the same protein modification which gives rise to the new polypeptide of apparent MW $15 \mathrm{kDa}$.

The assignment of the removed Bchl to the $\mathrm{M}$ branch $\left(\mathrm{Bchl}_{\mathrm{M}}\right)$ supports earlier kinetic results. The primary charge separation is not influenced by removal of one Bchl by treating RCs of $R b$. sphaeroides with borohydride (Maroti et al., 1985). It has been argued on this basis, that the Bchl removed is the one located on the 'inactive' or M side of the RC. In view of the yet undefined function of both Bchl pigments, this conclusion was not unambiguous, however, and has now been further substantiated.

\section{Differences in pigment interactions between modified and unmodified $R C$}

As discussed above, circular dichroism and lightinduced absorption changes (Maroti et al., 1985; Shuvalov et al., 1986) of modified and unmodified RC show distinct differences which indicate rather complex couplings of the related bands. Corresponding, albeit less pronounced, effects are also observed in Raman resonance spectra.

Knapp et al. (1986) were able to reproduce a variety of optical spectra in the NIR spectral region of the RC from $R p$. viridis based on the $\mathrm{x}$-ray data of Deisenhofer et al. (1984). More recently, this analysis has been extended to the RC of $R b$. sphaeroides and C. aurantiacus (Scherer and Fischer, 1986). Scherz and Parson (1984) have used a different approach which emphasizes the strong hyperchromism of the $Q_{y}$ at the expense of the shorter wavelength bands upon aggregation of chlorophylls, which is even more pronounced in the CD spectra. Both treatments point to the strong couplings existing among the pigments in $\mathrm{RC}$, such that most bands cannot be assigned to individual pigments but rather are of complex origin. The qualitative and quantitative changes observed upon removal of one of the six pigments support these couplings. The large signal decrease in the NIR and a much smaller decrease in the Soret can also be accounted for by hyperchromism. A full analysis of the spectral data is currently under way. which should also be a test case for the theoretical models on which the calculations are based.

The difference in the MIA spectra are another reflection of a change induced by the modification on the primary donor. At low excitation power, the observed spectrum is the difference between singlet and triplet absorption spectra of the primary donor and has been introduced under this name to photosynthetic systems (den Blanken and Hoff, 1983). It is thus selective to the primary donor, and it is also very sensitive due to the presence of a series of narrow bands in the $800 \mathrm{~nm}$ region. The spectral changes in the modified RC (Fig. 7) are very pronounced and indicate considerable differences in the coupling of the primary donor. The MIA spectra have recently been modelled for $\mathrm{RC}$ from three different bacteria (Knapp et al., 1986; Scherer and Fischer, 1987) on the basis of the x-ray data of the $\mathrm{RC}$ from Rp. viridis (Deisenhofer et al., 1984). A similar analysis assuming that $\mathrm{Bchl}_{\mathrm{M}}$ is removed in the modified $\mathrm{RC}$, gave a reasonably good fit of the experimental data (Scherer et al., to be published). Together with the Raman resonance data, we take this as further evidence that the major change induced by treatment with sodim borohydride, is indeed the removal of $\mathrm{Bchl}_{\mathrm{M}}$ as suggested originally by Ditson et al. (1984).

Acknowledgements-This work was supported by the Deutsche Forschungsgemeinschaft, 53 Bonn (SFB 143, project A1 in München, AZ Wo 41/37-1 in Stutgart). R. $S$. thanks for a binational grant from the French ministry of foreign affairs. We are indebted to Dr Reng at the Gellschaft für Biotechnologische Forschung, 3301 Stöckheim, for mass culture of $R b$. sphaeroides. We acknowledge the continuing support of Prof W. Rüdiger, and A. A. would like to thank Prof H. C. Wolf and Dr J. U. v. Schütz for their support.

\section{REFERENCES}

Angerhofer, A., J. U. von Schütz and H. C. Wolf (1984) Fluorescence-ODMR of reaction centers of Rhodopseudomonas viridis. Z. Naturforsch 39c, 1085-1090.

Angerhofer, A., J. U. von Schütz and H. C. Wolf (1985) 
Fluorescence-ODMR of light harvesting pigments of photosynthetic bacteria. Z, Naturforsch 40c, 379-387.

Angerhofer, A., R. J. Cogdell and M. F. Hipkins (1986) A spectral characterization of the light harvesting pigment-protein complexes from Rhodopseudomonas acidophila. Biochim. Biophys. Acta 848, 333-341.

Beck. J., J. U. von Schütz and H. C. Wolf (1983a) Optically detected magnetic resonance of porphyrin complexes in the bacterium Rhodopseudomonas sphaeroides. Z. Naturforsch 38c, 220-229.

Beck. J.. J. U. von Schütz and H. C. Wolf (1983b) Fluorescence-ODMR of chlorophyll in photosynthetic bacteria. I. Reaction centers of Rhodopseudomonas sphaeroides R26. Chem. Phys. Lett. 94, 141-146.

Breton, J., J. Deprez, B. Tavitian and E. Nabedryk (1986) Spectroscopy, structure and dynamics in the reaction center of Rhodopseudomonas viridis. Proc. VII lnt. Congr. Photosynthesis, (Edited by J. Biggins.) Vol. 1. pp. 387-394. Martinus Nijhoff, Dordrecht.

Chang, C. -H., D. Tiede, J. Tang, V. Smith, J. Norris and M. Schiffer (1986) Structure of Rhodopseudomonas sphaeroides R-26 reaction centers. FEBS 205, 82-86.

Clayton, R. K. and R. T. Wang (1971) Photochemical Reaction Centres from Rhodopseudomonas sphaeroides. Methods Enzymol. XXIII, 696.

Crestfield, A. M., S. Moore and W. H. Stein (1963) The preparation and enzymatic hydrolysis of reduced and $\mathrm{S}$ Carboxymethylated proteins. J. Biol. Chem. 238 , 622-627.

Deisenhofer, J., O. Epp, K. Miki. R. Huber and H. Michel (1984) X-ray structure analysis of a membrane protein complex. Electron density map at $3 \AA$ resolution and a model of the chromophores of the photosynthetic reaction center from Rhodopseudomonas viridis. J. Mol. Biol. 180, 385-398.

den Blanken, H. J. and A. J. Hoff (1983) Resolution enhancement of the triplet-singlet absorbance-difference spectrum and the triplet-ESR-spectrum in zero field by the selection of sites. An application to photosynthetic reaction center, Chem. Phys. Lett. 98. 255-262.

den Blanken, H. J. (1983) Ph.Thesis, Leiden.

den Blanken, H. J., H. Vasmel, A. P. Jongenelis, A. J. Hoff and J. Amesz (1985) The triplet-state of the primary donor of the green photosynthetic bacterium Chloroflexus aurantiacus. FEBS Lett. 161, 185-189.

Ditson, S. L., R. C. Davis and R. M. Pearlstein (1984) Relative enrichment of $P 870$ in photosynthetic reaction centers treated with sodium borohydride. Biochim. Biophys. Acta 766, 623-629.

Feher, G. and M. Y. Okamura (1978) Chemical Composition and Properties of Reaction Centers. In The Photosynthetic Bacteria. Clayton R. K. and W. R. Sistron (Eds), Chapter 19. Plenum Press, New York.

Fischer, S. F. and P. O. J. Scherer (1987) On the early charge separation and recombination processes in bacterial reaction centers. Chem. Phys. 115, 151-158.

Hoff, A. (1986) Magnetic interactions between photosynthetic reactants. Photochem. Photobiol. 43, 727-746.

Hoff, A. J., E. J. Lous, K. W. Moehl and J. A. Dijkman (1985) Magneto-optical absorbance difference spectroscopy. A new tool for the study of radical recombination reactions. An application to bacterial photosynthesis. Chem. Phys. Lett. 114, 39-43.

Holten, D., C. Kirmaier and L. Levine (1986) Picosecond studies of the kinetics and mechanisms of electron transfer in bacterial reaction centers. Proc. VII Int. Congr. Photosynthesis, (Edited by J. Biggins). Vol. I, pp. 169-176. Martinus Nijhoff, Dordrecht.

Knapp, E. W., S. F. Fischer, W. Zinth, M. Sander, W. Kaiser, J. Deisenhofer and H. Michel (1985) Analysis of optical spectra from single crystals of Rhodopseudo monas viridis reaction centers. Proc. Nall. Acad. Sci.
USA 82, 8463-8467.

Knapp, E. W., P. O. J. Scherer and S. F. Fischer (1986) Model studies to low temperature optical transitions of photosynthetic reaction centers. A-, LD-, CD-, ADMR-, and LD-ADMR- spectra for Rhodopseudomonas viridis. Biochim. Biophys. Acta 852. 295-305.

Laemmli, V. K. (1970) Cleavage of structural proteins during the assembly of the head of bacteriophage $T 4$. Nature 227, 680-685.

Lutz, M. and B. Robert (1987) Chlorophylls and the photosynthetic membrane. Biological Applications of Raman Spectroscopy, (Edited by T. G. Spire), Vol. III, Chapter 9. Wiley, New York.

Lutz, M. and B. Robert (1985) Probing photosynthetic structures using resonance Raman spectroscopy of their pigments. In Proc. of 1st Eur. Conf. Spectroscopy of Biological Molecules; Reims, France, (Edited by A. J P. Alix, L. Bernard, M. Manfait), pp. 310-318. John Wiley and Sons, New York.

Maroti, P., C. Kirmaier, C. Wraight, D. Holten and R. M. Pearlstein (1985) Photochemistry and electron transfer in borohydride-treated photosynthetic reaction centers. Biochim. Biophys. Acta 810, 132-139

Martin, J. -L., J. Breton, A. J. Hoff, A. Migus and A Antonetti (1986) Femtosecond spectroscopy of electron transfer in the reaction center of the photosynthetic bacterium Rhodopseudomonas sphaeroides $R-26$ : Direct electron transfer from the dimeric bacteriochlorophyll primary donor to the bacteriopheophytin acceptor with a time constnat of $2.8 \pm 0.2$ psec. Proc. Natl. Acad. Sci. USA 83, 957-961.

Michel-Beyerle, M. E., M. Plato, J. Deisenhofer, H Michel, M. Bixon and J. Jornter (1987) Unidirectionality of charge separation in reaction centers of photosynthetic bacteria. Biochim. Biophys. Acta. In press.

Norris, J. R., H. Scheer, M. E. Druyan and J. J. Katz (1974) An electron-nuclear double resonance (Endor) study of the special pair model for photo-reactive chlorophylls in photosynthesis. Proc. Natl. Acad. Sci. USA 71, 4897-4900.

Norris, J. R., H. Scheer and J. J. Katz (1975) Models for antenna and reaction center chlorophylls. Ann. N. Y. Acad. Sci. 244, 260-280.

Ogrodnik, A., H. W. Krüger, H. Orthuber, R. Haberkorn, M. E. Michel-Beyerle and H. Scheer (1982) Recombination dynamics in bacterial photosynthetic reaction centers. Biophys. J. 39. 91-99.

Parson, W. W. (1982) Photosynthetic bacterial reaction centers: Interactions among the bacteriochlorophylls and bacteriopheophytins. Annu. Rev. Biophys. Bioeng. 11, $57-80$.

Reed, D. W. and B. Ke (1973) Spectral properties of reaction center preparations from Rhodopseudomonas sphaeroides. J. Biol. Chem. 248, 3041-3045.

Robert, B., M. Lutz and D. M. Tiede (1985) Selective photochemical reduction of either of the two bacteriopheophytins in reaction centers of Rhodopseudomonas sphaeroides $R-26$. FEBS 183, 326-330.

Robert, B., R. Steiner, Q. Zhou, H. Scheer and M. Lutz (1986) Structures of antenna complexes and reaction centers from bacteriochlorophyll b-containing bacteria: Resonance raman studies. Proc. VII Int. Congr. Photosynthesis, (Edited by J. Biggins). Vol. I, pp. 411-414. Martinus Nijhoff, Dordrecht.

Scherer, P. O. J. and S. F. Fisher (1987) Model studies to low temperature optical transitions of photosynthetic reaction centers II: Rhodopseudomonas sphaeroides and Chloroflexus aurantiacus. Biochim. Biophys. Acta 891 , 157-164.

Scherz, A. and W. W. Parson (1984) Exciton interactions in dimers of bacteriochlorophyll and related molecules. Biochim. Biophys. Act 766, 666-678.

Shuvalov, V. A. and L. N. M. Duysnes (1986) Primary 
electron transfer reactions in modified reaction centers from Rhodopseudomonas sphaeroides. Proc. Natl. Acad. Sci. USA 83, 1690-1694.

Shuvalov, V. A., A. Ya. Shkuropatov, S. M. Kulakova M. A. Ismailov and V. A. Shkuropatova (1986) Photoreactions of bacteriopheophytins and bacteriochlorophylls in reaction centers of Rhodopseudomonas sphaeroides and Chloroflexus aurantiacus. Biochim. Biophys. Acta 849, 337-346.

Smith, J. R. L. and M. Calvin (1966) Studies of the chemical and photochemical oxidation of bacteriochlorophyll. J. Am. Chem. Soc. 88, 4500-4506.

Steiner, R., B. Kalumenos and H. Scheer (1986) The photosynthetic apparatus of Ectothiorhodospira halochloris 3. Effect of proteolytic digestion on the photoactivity. Z. Naturforsch. 41c, 873-880.

Theiler, R., F. Suter, H. Zuber and R. J. Cogdell (1984) A comparison of the primary structures of the two $B$ 800-850-apoproteins from wild-type Rhodopseudo- monas sphaeroides strain 2.4.1. and a carotenoidless mutant strain $\mathrm{R} 26.1$ FEBS 175, 231-237.

Vermeglio, A. and G. Paillotin (1982) Structure of Rhodopseudomonas viridis reaction centers, absorption and photoselection at low-temperature. Biochim. Biophys. Acta 681, 32-40.

Wasielewski, M. R. (1986) Ultrafast electron and energy transfer in reaction center and antenna proteins from photosynthetic bacteria. VII Int. Congr. Photosynthesis. Unpublished.

Wiemken, V. and R. Bachofen (1984) Probing the smallest functional unit of the reaction center of Rhodospirillum rubrum $G 9$ with proteinases. FEBS Lett. 166. 155-159.

Zinth, W., M. C. Nuss, M. A. Franz, W. Kaiser and H. Michel (1983) In Antennas and Reaction Centers of Photosynthetic Bacteria. (Edited by M. E. MichelBeyerle). pp. 286-291. Springer, Berlin.

Note added in proof. Drs Shuvalov and Shkuropatov have communicated to us that the room temperature CD spectra published in Shuvalov et al. (1986) were normalized at $870 \mathrm{~nm}$. The decrease in modified RC was less than $20 \%$. In view of the lesser degree of modification (judged from the ratio of the 800 and $870 \mathrm{~nm}$ absorption bonds). this value is compatible with our data. 